\title{
Comparison of the Efficacy of EGFR Tyrosine Kinase Inhibitors Erlotinib and Low-dose Osimertinib on a PC-9-GFP EGFR Mutant Non-small-cell Lung Cancer Growing in the Brain of Nude Mice
}

\author{
YUKI KATSUYA $^{1,2}$, KENTARO MIYAKE $^{1,2}$, TAKASHI HIGUCHI $^{1,2}$, HIROMICHI OSHIRO $^{1,2}$, \\ NORIHIKO SUGISAWA ${ }^{1,2}$, SHREE RAM SINGH ${ }^{3}$, YASUSHI GOTO ${ }^{4}$, MING ZHAO ${ }^{1}$ and ROBERT M. HOFFMAN ${ }^{1,2}$ \\ ${ }^{1}$ AntiCancer, Inc., San Diego, CA, U.S.A.; \\ ${ }^{2}$ Department of Surgery, University of California, San Diego, CA, U.S.A.; \\ ${ }^{3}$ Basic Research Laboratory, Center for Cancer Research, National Cancer Institute, Frederick, MD, U.S.A.; \\ ${ }^{4}$ Department of Thoracic Oncology, National Cancer Center, Tokyo, Japan
}

\begin{abstract}
Background/Aim: Brain metastases are found in approximately $30 \%$ of patients with epidermal-growth-factor receptor (EGFR) mutant non-small cell lung cancer (NSCLC). We compared the efficacy of two EGFR-tyrosine kinase inhibitors (TKIs), erlotinib and osimertinib on a PC9-GFP EGFR mutant NSCLC growing in the brain of nude mice. Materials and Methods: The brain metastasis models were randomized into five groups and treated for 15 days. Control; $5 \mathrm{mg} / \mathrm{kg}$ erlotinib; $50 \mathrm{mg} / \mathrm{kg}$ erlotinib; $0.5 \mathrm{mg} / \mathrm{kg}$ osimertinib; $5 \mathrm{mg} / \mathrm{kg}$ osimertinib. Tumor volume was evaluated by non-invasive fluorescence imaging. Results: Only $5 \mathrm{mg} / \mathrm{kg}$ osimertinib, a low-dose compared to the clinically-equivalent dose, showed significant tumor regression compared to the control. Conclusion: This study strongly supports the high activity of osimertinib for intracranial lesions of EGFR-mutant NSCLC.
\end{abstract}

Lung cancer is the leading cause of cancer-related deaths worldwide (1) and in the United States (2). Non-small-cell lung cancer (NSCLC) has several predictive biomarkers such as EGFR, $A L K, R O S 1$, and BRAF. Targeted drugs against NSCLCs that carry such mutations have prolonged the

This article is freely accessible online.

Correspondence to: Robert M. Hoffman, AntiCancer, Inc., 7917 Ostrow St., San Diego, CA 92111, U.S.A. Tel: +1 8586542555, Fax: +1 8582684175, e-mail: all@anticancer.com; Shree Ram Singh, Basic Research Laboratory, National Cancer Institute, Frederick, MD 217021201, U.S.A. Tel: +1 3018467331, e-mail: singhshr@mail.nih.gov

Key Words: Erlotinib, osimertinib, PC-9-GFP, non-small cell lung cancer, nude mice. survival time of patients with NSCLC. Approximately $30 \%$ of patients with EGFR mutant NSCLC have brain metastases at the time of diagnosis (3), and the control of brain metastases is essential for survival. The $1^{\text {st }}$ and $2^{\text {nd }}$ generation EGFRtyrosine kinase inhibitors (EGFR-TKIs), erlotinib, gefitinib, and afatinib, had only partial efficacy on brain metastases, with $60-80 \%$ response rates in studies of a limited number of patients (4). The $3^{\text {rd }}$ generation EGFR-TKI, osimertinib, has high central nervous system (CNS) activity both in clinical studies (5) and in pre-clinical studies. Osimertinib has a high brain:plasma Cmax ratio compared to other EGFR-TKIs, as shown in pre-clinical studies (6), suggesting that osimertinib has potential to have efficacy on brain metastases.

We have previously demonstrated that a clinicallyequivalent dose of $25 \mathrm{mg} / \mathrm{kg}$ of osimertinib had strong efficacy against the PC-9 green fluorescent protein expressing (PC-9-GFP) EGFR mutant NSCLC growing in the brain of nude mice, compared to the cytotoxic drugs cisplatinum and pemetrexed (7). In the present study, we compared the efficacy of the $1^{\text {st }}$-generation EGFR-TKI erlotinib, and the $3^{\text {rd }}$-generation EGFR-TKI osimertinib, at a low dose, on the PC-9-GFP brain model.

\section{Materials and Methods}

Cell line. GFP-expressing PC-9 (NSCLC, EGFR exon 19 deletion)GFP cells (AntiCancer, Inc., San Diego, CA, USA) were maintained in RPMI-1640 medium (Mediatech, Inc. Manassas, VA, USA) supplemented with $10 \%$ fetal bovine serum, $100 \mathrm{U} / \mathrm{ml}$ penicillin and $100 \mu \mathrm{g} / \mathrm{ml}$ streptomycin. Cells were cultured at $37^{\circ} \mathrm{C}$ with $95 \%$ air and $5 \% \mathrm{CO}_{2}$, and split $48 \mathrm{~h}$ prior to inoculation to ensure they were in log growth phase when harvested. Then, cells were re-suspended at a concentration of $4 \times 10^{7}$ cells $/ \mathrm{ml}$ in serum-free RPMI medium. Suspended cells were well mixed with ice-thawed Matrigel at 1:1 ratio for inoculation (7). 
Experimental animals. Athymic nude (nu/nu) male mice (6-8 week AntiCancer, Inc., San Diego, CA, USA) were utilized. Animal housing and their diet were as previously described (7). Mice were observed on a daily basis and humanely sacrificed by $\mathrm{CO}_{2}$ inhalation with humane endpoint criteria as previously described (7).

Tumor stock preparation using subcutaneous models. Nude female mice (5-6) weeks were used for tumor stock. Each mouse received a subcutaneous cancer-cell inoculation in both flanks with a $0.1 \mathrm{ml}$ inoculum of $2.0 \times 10^{6}$ cells. Once the tumor diameter reached approximately $10 \mathrm{~mm}$, the mouse was anaesthetized and euthanized in order to resect the tumor (7)

Establishment of brain implantation model. Subcutaneous tumors were harvested and cut into small fragments (2-3 mm in diameter). Mice were anesthetized with a subcutaneous ketamine mixture. An 8 -mm sagittal incision of the scalp was made to expose the skull. A $5 \mathrm{~mm} \mathrm{v}$-shaped flap on the skull was made. Each tumor fragment was implanted between the bone flap and brain. The skin was closed with a surgical suture (7).

Randomization and Initiation of treatment. Group randomization took place the day prior to the dosing day (day 0) based on the condition of the animals. Treatment was started 3 weeks later in the brain models when the tumor GFP fluorescent area reached $8-60 \mathrm{~mm}^{2}$.

Treatment protocol. The mice were randomized into 5 groups of 10 mice each; G1: control group [vehicle (PBS + 1\% DMSO), $0.1 \mathrm{ml} / 10$ $\mathrm{g}$ body weight, oral administration (p.o.), once daily (qd)]; G2: erlotinib $5 \mathrm{mg} / \mathrm{kg}$ + vehicle, $0.1 \mathrm{ml} / 10 \mathrm{~g}$ body weight, p.o., qd; $\mathrm{G} 3$ : erlotinib $50 \mathrm{mg} / \mathrm{kg}$ + vehicle, $0.1 \mathrm{ml} / 10 \mathrm{~g}$ body weight, p.o., qd; G4: osimertinib $0.5 \mathrm{mg} / \mathrm{kg}$ + vehicle, $0.1 \mathrm{ml} / 10 \mathrm{~g}$ body weight, p.o., qd; G5: osimertinib $5 \mathrm{mg} / \mathrm{kg}$ + vehicle, $0.1 \mathrm{ml} / 10 \mathrm{~g}$ body weight, p.o., qd.

Mice were observed daily for general mobility, morbidity and mortality. Body weight was evaluated twice a week. Mouse deaths were assessed as tumor-related, drug-related, technical, or of unknown reason based on factors including gross observation and weight loss and number and day of death in each group. Signs of toxicity were monitored, including cachexia, diarrhea, skin rash and color. Animals were sacrificed 15 days after treatment initiation, or earlier, if mice became moribund.

Imaging. A FluorVivo Small Animal Imaging System (INDEC BioSystems, Santa Clara, CA, USA) was used for fluorescence imaging. Tumor volume was calculated by multiplying fluorescent tumor area $\left(\mathrm{mm}^{2}\right)$ and fluorescence intensity $(\% \times 1 / 100)$.

Statistical analysis. All statistical analyses were performed with EZR (http://www.jichi.ac.jp/saitama-sct/SaitamaHP.files/statmed.html). Statistical analysis of tumor volume and body weight was performed using the Student's $t$-test to compare differences among treatment groups. The Kruskal-Wallis test was performed as a non-parametric test. A probability value of $p<0.05$ was considered as statistically significant.

Ethical considerations. All experiments were done at AntiCancer Inc. with an Institutional Animal Care and Use Committee (IACUC)-protocol solely approved for the study and following the principles and procedures defined in the National Institutes of Health (NIH) Guide for the Care and Use of Animals under Assurance Number A3873-1.

\section{Results}

Treatment efficacy evaluated by tumor volume. GFP fluorescent area and fluorescence intensity were used to calculate tumor volume on days 0 and 15 after treatment. The tumor volume ratio change of each group (day 15/day 0 ) is shown in Figure 1A. Five $\mathrm{mg} / \mathrm{kg}$ osimertinib (G5; mean $\pm \mathrm{SD} ; 0.79 \pm 0.48$ ) led to a significant tumor volumeratio reduction compared to the control group $(\mathrm{G} 1$; mean $\pm \mathrm{SD} ; 1.65 \pm 0.78)(p=0.022)$. Other groups did not show a significant tumor volume-ratio reduction: $5 \mathrm{mg} / \mathrm{kg}$ elrotinib $(\mathrm{G} 2$; mean $\pm \mathrm{SD} ; 2.04 \pm 0.91), 50 \mathrm{mg} / \mathrm{kg}$ elrotinib (G3; mean $\pm \mathrm{SD} ; \quad 1.50 \pm 0.83), \quad 0.5 \mathrm{mg} / \mathrm{kg}$ osimertinib (G4; mean \pm SD; $2.28 \pm 1.77)$. Representative images of mice with growth or shrinkage of the tumor are shown in Figure 1B.

Body weight change. The body weight ratio of each group (day 15/day 1) showed no significant difference among groups (G1 control group; mean $\pm \mathrm{SD}$; 0.96 \pm 0.14 , G2 $5 \mathrm{mg} / \mathrm{kg}$ erlotinib; mean $\pm \mathrm{SD} ; 0.85 \pm 0.17$, G3 $50 \mathrm{mg} / \mathrm{kg}$ erlotinib; mean $\pm \mathrm{SD} ; 0.98 \pm 0.04$, G4 $0.5 \mathrm{mg} / \mathrm{kg}$ osimertinib; mean $\pm \mathrm{SD}$; $0.94 \pm 0.05$, G5 $5 \mathrm{mg} / \mathrm{kg}$ osimertinib; mean $\pm \mathrm{SD} ; 0.99 \pm 0.11$ ), although G2 showed relatively low body weight because of insufficient antitumor effect (Figure 2).

Cause of deaths and adverse events. During 15 days of treatment, the cause of death in each group was as follows: Two died in G1 control group (1 was tumor-related, and 1 was technical). Three died in G2 $5 \mathrm{mg} / \mathrm{kg}$ erlotinib ( 2 were tumorrelated, and 1 was technical). Three died in $\mathrm{G} 350 \mathrm{mg} / \mathrm{kg}$ erlotinib (1 was tumor-related, and 2 were others or unknown). One died in G4 $0.5 \mathrm{mg} / \mathrm{kg}$ osimertinib (tumor-related). Two died in G5 $5 \mathrm{mg} / \mathrm{kg}$ osimertinib (both were tumor-related). One adverse event, which was related to treatment, was seen in $\mathrm{G} 350 \mathrm{mg} / \mathrm{kg}$ erlotinib: occasional soft stool in one mouse. Overall, treatment was tolerable in all groups.

\section{Discussion}

For the brain model of PC-9-GFP NSCLC nude mice, 5 $\mathrm{mg} / \mathrm{kg}$ osimertinib showed a significant reduction in tumor volume compared to the control. No significant difference was seen in the change in body weight or toxicities between the control group, erlotinib, and osimertinib treatment groups.

Our study, using the relatively low dose $(5 \mathrm{mg} / \mathrm{kg} \mathrm{qd})$ of osimertinib, strongly supports the superior activity of osimertinib for brain metastasis of EGFR mutant NSCLC compared to erlotinib. Osimertinib was developed for NSCLC EGFR T790M resistance mutant. The search for EGFR sensitizing mutations (exon 19 del and L858R mutations) is still ongoing. We observed that $0.5 \mathrm{mg} / \mathrm{kg} \mathrm{qd}$ osimertinib was not sufficient for intracranial tumor shrinkage. The $5 \mathrm{mg} / \mathrm{kg}$ osimertinib used in the present study 
A

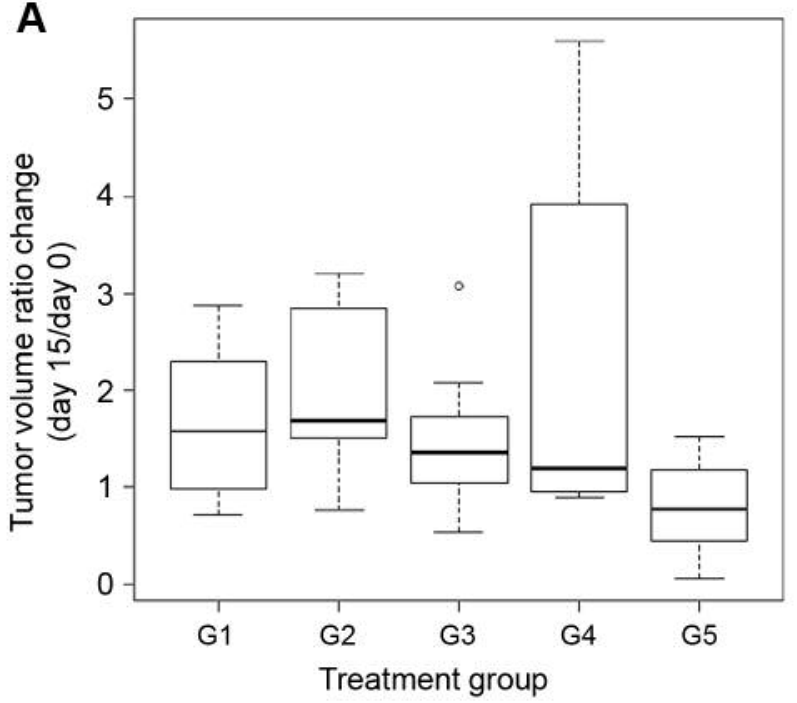

B

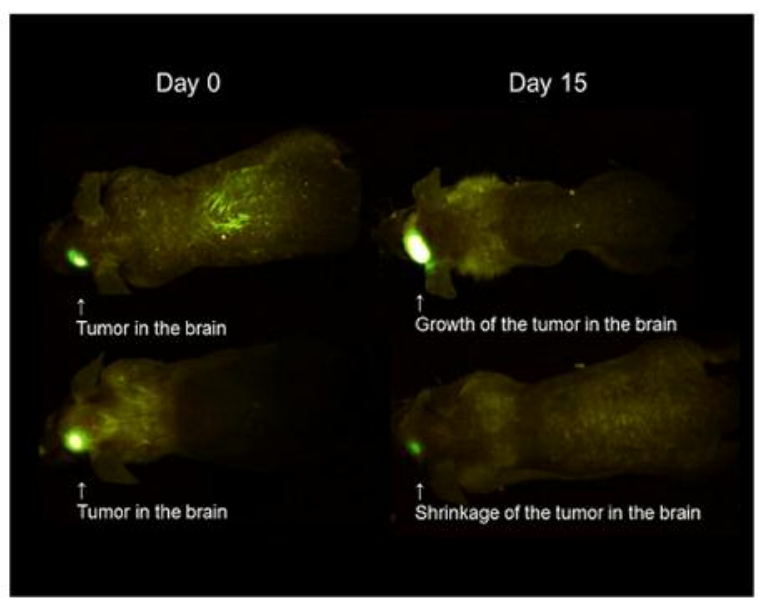

Figure 1. Drug efficacy and tumor volume. (A) Tumor-volume ratio change in each treatment group. G1: Control; G2: erlotinib $5 \mathrm{mg} / \mathrm{kg}$; G3: erlotinib $50 \mathrm{mg} / \mathrm{kg}$; G4: osimertinib $0.5 \mathrm{mg} / \mathrm{kg}$; G5: osimertinib $5 \mathrm{mg} / \mathrm{kg}$. In the box and whisker plots, the horizontal line within the box indicates the median, boundaries of the box indicate the $25^{t h}$ - and $75^{\text {th }}$ - percentile, and the error bars indicate the highest and lowest values of the results. (B) Representative images of tumor volume change. The upper mouse was in G2 and the lower mouse was in G5.

is five times less than the dose we used in our previous study, which was a clinically-equivalent dose (7), but had similar efficacy against the PC-9-GFP NSCLC nude-mouse brain model. The high efficacy of osimertinib for brain metastasis has been previously explained by the high bloodbrain barrier penetration (6).

For patients with EGFR mutant NSCLC, treatment options for asymptomatic brain metastasis are radiation therapy and systemic therapy such as EGFR-TKIs. An ideal treatment sequence has not been determined yet by prospective clinical studies. Several prospective clinical studies to consider this clinical question have been reported: $1^{\text {st- }}$ generation EGFRTKI, gefitinib, showed favorable response on brain metastatic lesions in a Phase II study (8). Osimertinib showed better central nervous system efficacy compared to cytotoxic agents (platinum-pemetrexed) in the subset analysis of a Phase III study (9). Response rates of the intracranial lesions were higher for osimertinib, $91 \%$, compared to gefitinib or erlotinib, $68 \%$, in the subset analyses of a Phase III study (10). Accumulated clinical data and tolerable adverse events of EGFR-TKIs, compared to cytotoxic agencies or radiation therapy, favor systemic treatment with EGFR-TKIs for EGFR mutant NSCLC with asymptomatic brain metastasis.

In terms of the tumor regression efficacy, $5 \mathrm{mg} / \mathrm{kg}$ of osimertinib showed significant benefit in brain-implanted GFP-labeled EGFR mutant NSCLC in nude mice, and is superior to erlotinib, an earlier generation EGFR-TKI. It is noteworthy, that $5 \mathrm{mg} / \mathrm{kg}$ of osimertinib was as active as the clinically-equivalent $25 \mathrm{mg} / \mathrm{kg}$ dose in our previous study in

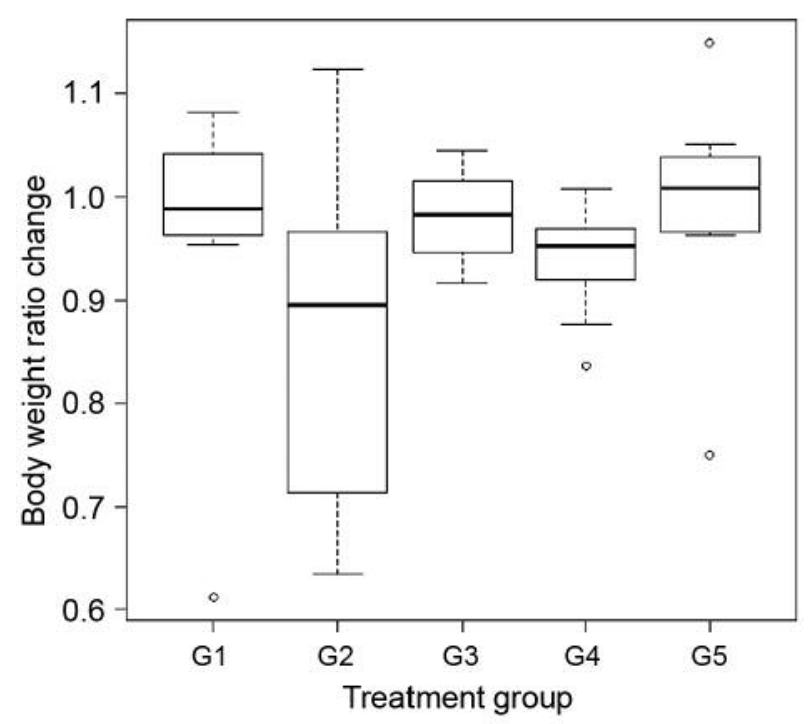

Figure 2. Body weight. Body weight ratio change (day 15/day 1) in each treatment group. G1: Control; G2: erlotinib $5 \mathrm{mg} / \mathrm{kg}$; G3: erlotinib 50 $\mathrm{mg} / \mathrm{kg}$; G4: osimertinib $0.5 \mathrm{mg} / \mathrm{kg}$; G5: osimertinib $5 \mathrm{mg} / \mathrm{kg}$. In the box and whisker plots, the horizontal line within the box indicates the median, boundaries of the box indicate the $25^{\text {th }}$ - and $75^{\text {th }}$ - percentile, and the error bars indicate the highest and lowest values of the results.

the PC-9-GFP NSCLC brain model in nude mice, further indicating the potential of osimertinib and the importance of orthotopic models to study clinically relevant drug targeting of tumors (11). 


\section{Conflicts of Interest}

AntiCancer Inc. uses PDOX models for contract research. YK, KM, $\mathrm{TH}, \mathrm{HO}, \mathrm{NS}, \mathrm{MZ}$ and RMH are or were unsalaried associates of AntiCancer Inc. There are no other competing financial interests.

\section{Authors' Contributions}

Conception and design: YK and RMH. Acquisition of data: YK, $\mathrm{KM}, \mathrm{TH}, \mathrm{HO}$, and NS. Analysis and interpretation of data: YK, KM, TH, HO, NS, MZ, SRS, YG and RMH. Writing, review, and/or revision of the manuscript: YK, RMH, and SRS.

\section{Acknowledgements}

This paper is dedicated to the memory of AR Moossa, MD, Sun Lee, MD, Professor Li Jia Xi, and Masaki Kitajima, MD.

\section{References}

1 World Health Organization/Fact Sheets/Cancer, 12 Sep 2018. Available at: https://www.who.int/news-room/fact-sheets/detail/ cancer

2 Cancer Stat Facts, 2019. Available at: https://seer.cancer.gov/ statfacts/html/common.html.

3 Iuchi T, Shingyoji M, Itakura M, Yokoi S, Moriya Y, Tamura H, Yoshida Y, Ashinuma H, Kawasaki K, Hasegawa Y, Sakaida T and Iizasa T: Frequency of brain metastases in non-small-cell lung cancer, and their association with epidermal growth factor receptor mutations. Int J Clin Oncol 20(4): 674-679, 2015. PMID: 25336382. DOI: 10.1007/s10147-014-0760-9

4 Dempke WC, Edvardsen K, Lu S, Reinmuth N, Reck M and Inoue A: Brain metastases in NSCLC - are TKIs changing the treatment strategy? Anticancer Res 35(11): 5797-5806, 2015. PMID: 26504000.

5 Soria JC, Ohe Y, Vansteenkiste J, Reungwetwattana T, Chewaskulyong B, Lee KH, Dechaphunkul A, Imamura F, Nogami N, Kurata T, Okamoto I, Zhou C, Cho BC, Cheng Y, Cho EK, Voon PJ, Planchard D, Su WC, Gray JE, Lee SM, Hodge R, Marotti M, Rukazenkov Y, Ramalingam SS and FLAURA Investigators: Osimertinib in untreated EGFR-mutated advanced non-small-cell lung cancer. N Engl J Med 378(2): 113125, 2018. PMID: 29151359. DOI: 10.1056/NEJMoa1713137
6 Ballard P, Yates JW, Yang Z, Kim DW, Yang JC, Cantarini M, Pickup K, Jordan A, Hickey M, Grist M, Box M, Johnström P, Varnäs K, Malmquist J, Thress KS, Jänne PA and Cross D: Preclinical comparison of osimertinib with other EGFR-TKIs in EGFR-mutant NSCLC brain metastases models, and early evidence of clinical brain metastases activity. Clin Cancer Res 22(20): 5130-5140, 2016. PMID: 27435396. DOI: 10.1158/ 1078-0432.CCR-16-0399

7 Higuchi T, Oshiro H, Zhang Z, Miyake K, Sugisawa N, Katsuya Y, Yamamoto N, Hayashi K, Kimura H, Miwa S, Igarashi K, Zhao M, Bouvet M, Singh SR, Tsuchiya H and Hoffman RM: Osimertinib regresses an EGFR-mutant cisplatinum- resistant lung adenocarcinoma growing in the brain in nude mice. Transl Oncol 12(4): 640-645, 2019. PMID: 30807997. DOI: 10.1016/ j.tranon.2019.01.007

8 Iuchi T, Shingyoji M, Sakaida T, Hatano K, Nagano O, Itakura M, Kageyama H, Yokoi S, Hasegawa Y, Kawasaki K and Iizasa T: Phase II trial of gefitinib alone without radiation therapy for Japanese patients with brain metastases from EGFR-mutant lung adenocarcinoma. Lung Cancer 82(2): 282-287, 2013. PMID: 24021541. DOI: 10.1016/j.lungcan.2013.08.016

9 Wu YL, Ahn MJ, Garassino MC, Han JY, Katakami N, Kim HR, Hodge R, Kaur P, Brown AP, Ghiorghiu D, Papadimitrakopoulou VA and Mok TSK: CNS efficacy of osimertinib in patients with T790M-positive advanced non-small-cell lung cancer: data from a randomized phase III trial (AURA3). J Clin Oncol 36(26): 27022709, 2018. PMID: 30059262. DOI: 10.1200/JCO.2018.77.9363

10 Reungwetwattana T, Nakagawa K, Cho BC, Cobo M, Cho EK, Bertolini A, Bohnet S, Zhou C, Lee KH, Nogami N, Okamoto I, Leighl N, Hodge R, McKeown A, Brown AP, Rukazenkov Y, Ramalingam SS and Vansteenkiste J: CNS response to osimertinib versus standard epidermal growth factor receptor tyrosine kinase inhibitors in patients with untreated EGFR-mutated advanced nonsmall-cell lung cancer. J Clin Oncol 36(33): 3290-3297, 2018. PMID: 30153097. DOI: 10.1200/JCO.2018.78.3118

11 Hoffman RM: Orthotopic is orthodox: Why are orthotopic-transplant metastatic models different from all other models? J Cell Biochem 56(1): 1-3, 1993. PMID: 7806583. DOI: 10.1002/jcb.240560102

Received February 26, 2020 Revised March 10, 2020 Accepted March 11, 2020 